\title{
Ciência na rede: a comunicação pública da ciência da UFU na mídia digital ${ }^{1}$
}

\author{
Anna Victória F. ROCHA ${ }^{2}$ \\ Camila Romão MARIANO ${ }^{3}$ \\ Heloir Cristiano SCHWAICKARDT ${ }^{4}$ \\ Adriana C. OMENA SANTOS ${ }^{5}$ \\ Universidade Federal de Uberlândia, Uberlândia, MG
}

\section{RESUMO}

O artigo em questão tem como objetivo apresentar análise de conteúdo parcial de dados coletados em projeto de iniciação científica financiado pelo CNPq, cujo fim é analisar se e de que forma as pesquisas científicas realizadas no âmbito da Universidade Federal de Uberlândia são abordadas pela mídia digital, em especial aquelas com maior penetração na cidade. $O$ trabalho também discorre sobre a presença crescente da ciência em nosso cotidiano e o modo como a comunicação pública eficiente pode se converter num importante instrumento de inclusão social, cidadania e popularização da ciência.

PALAVRAS-CHAVE: Comunicação pública da ciência, ciência e tecnologia, jornalismo científico, Universidade Federal de Uberlândia.

\section{Introdução}

Para melhor entender a sociedade contemporânea e a onipresença da ciência, que a caracteriza em diversos setores, vale a pena regressar ao fim da Idade Média e compreender a enorme ruptura que significou a passagem do medievo para a Modernidade.

Quando a figura de Deus abandona o eixo de significação da existência, colocando, então, o homem no centro de todas as coisas, os fenômenos naturais e também sociais, que antes eram justificados pela fatalidade divina, agora precisam de um novo sentido. Observa-se, então, aquilo que o sociólogo francês Gilles Lipovetsky (2000, p. 23) chama de "racionalização social moderna”. Neste contexto, a ciência é o meio encontrado pelo homem para desmistificar o mundo, desvendando-o com suas

1 Trabalho apresentado no IJ 06 - Interfaces Comunicacionais - Intercom Júnior - Jornada de Iniciação Científica em Comunicação do XIX Congresso de Ciências da Comunicação na Região Sudeste, realizado de 22 a 24 de maio de 2014.

2 Estudante de Graduação no curso de Comunicação Social: Habilitação em Jornalismo da Universidade Federal de Uberlândia, email: rocha.annavitoria@gmail.com .

3 Estudante de Graduação no curso de Jornalismo da Universidade Federal de Uberlândia e bolsista de Iniciação Científica junto ao CNPQ , email: camila-romao17@hotmail.com

4 Estudante de Graduação no curso de Jornalismo da Universidade Federal de Uberlândia e bolsista no Programa de Educação Tutorial - PET Conexões de Saberes - Educomunicação, email: heloircristiano@gmail.com

5 Orientador do trabalho. Coordenadora do programa de Pós-graduação em Tecnologias, Comunicação e Educação e professora do Comunicação Social: Habilitação em Jornalismo da UFU, email: adriomena@gmail.com . 
próprias faculdades e, em seguida, usufruindo daquilo que ele tem a oferecer da forma mais utilitária e racional possível.

A associação deste momento particular da sociedade ocidental com uma época de iluminação fez com que o século XVIII ficasse conhecido como o século das Luzes. Em 1783, Immanuel Kant escreve que vivemos uma época de Esclarecimento (Aufklärung), um momento crucial de saída da menoridade - definida pelo alemão como o estado do homem que não pensa por si próprio, mas depende dos outros para tanto -, associada ao teocentrismo. De acordo com o filósofo, o homem é o responsável por essa condição de ignorância, pois lhe falta determinação e coragem suficientes para abandonar a tutela do outro e passar a servir-se de seu próprio entendimento (KANT, 2005).

É importante destacar, contudo, uma pontuação interessante feita por Kant no mesmo trabalho: o autor reconhece que um dos grandes entraves que a humanidade enfrenta para abandonar sua menoridade é o medo do desconhecido, o receio de caminhar sobre as próprias pernas. Por isso, é para ele “praticamente inevitável” que um público se esclareça:

\footnotetext{
Pois então sempre se encontrarão alguns homens pensando por si mesmos, incluindo os tutores oficiais da grande maioria, que, após terem eles mesmos rejeitado o jugo da minoridade, difundirão o espírito de uma apreciação razoável de seu próprio valor e a vocação de cada homem de pensar por si mesmo. (KANT, 2005, p. 64)
}

Para que isto ocorra, a humanidade necessita apenas da "liberdade de fazer o uso público de sua razão em todos os domínios” (KANT, 2005, p. 65). Kant é categórico ao afirmar que apenas o uso público da razão é capaz de fazer com que a iluminação, ou o Esclarecimento, atinja e liberte a todos os homens.

Avançando alguns anos na discussão, trazemos esta questão para nosso tempo ao pensarmos, inicialmente, na Declaração Universal dos Direitos Humanos, que prevê, em seu XIX artigo, o direito tanto à informação como também às liberdades de expressão e opinião. É notável que este cuidado em assegurar aos homens o direito de informar-se e disseminar informação pode ser ligado ao entendimento da importância do uso público da razão discutido por Kant quase dois séculos antes. Tais liberdades são, como já foi dito, as condições necessárias para que a humanidade ascenda às Luzes e abandone a menoridade a qual esteve por muito tempo condenada. 


\section{A Ciência e Comunicação Pública}

Tais noções teóricas e históricas são seminais quando queremos falar de comunicação pública da ciência (CPC), que Heloiza Matos define como sendo o “debate que se dá na esfera pública entre Estado, governo e sociedade, sobre temas de interesse coletivo. Um processo de negociações através da comunicação, próprio das sociedades democráticas” (apud DUARTE, 2009, p. XI). Ainda acerca do conceito, Elizabeth Pazito Brandão compreende a mesma como "um processo comunicativo das instâncias da sociedade que trabalham com a informação voltada para cidadania” (apud DUARTE, 2009, p. 5).

A comunicação pública pode ainda ser vista como a interlocução entre Estado e Sociedade, uma vez que Duarte e Veras (2006) compreendem que “o direito à informação que é assegurado igualmente a cada indivíduo, como garantia de serem informados e de poder se informar de todos os acontecimentos com os quais, de alguma maneira, tenham relação". Da mesma forma, em artigo no qual se propõe elencar as diversas concepções do termo, Brandão (2006) fala sobre a comunicação pública identificada com a comunicação científica, a qual nos interessa neste trabalho primordialmente, e aproxima a ciência da comunicação em consideração ao crescimento em importância da primeira com relação à opinião pública.

Há quem diga que o papel do profissional de comunicação, mais especificamente do jornalista, é criar uma ponte entre o mundo e o leitor, definição apropriada quando pensamos no caso específico da ciência, cujo universo ainda é um grande mistério para o homem comum. Assim, um profissional da comunicação que se aventure na área científica deve traduzir a linguagem e as questões dos laboratórios e centros de pesquisa para uma língua que seu público entenda, para que então compreenda o que está sendo feito e, mais importante, qual a relevância daquilo e em que medida a criação de um punhado de novos algoritmos, por exemplo, pode mudar sua vida.

Importante não apenas do ponto de vista do conhecimento, uma comunicação eficaz a respeito de ciência e tecnologia é também instrumento e aliada importante na construção da democracia participativa, essencial para o exercício pleno da cidadania. Esta preocupação encontra-se presente na análise feita por Brandão a respeito do 
panorama da comunicação pública no Brasil: a pesquisadora conclui que "um ponto comum de entendimento que é aquele que diz respeito a um processo comunicativo que se instaura entre o Estado, o governo e a sociedade com o objetivo de informar para construir a cidadania”. (BRANDÃO, 2006, p. 10)

\section{O papel da Universidade na divulgação científica/popularização da ciência}

Esta vinculação direta da comunicação pública com as instituições públicas, faz pensar acerca do papel das universidades públicas na construção desta ponte entre sociedade e comunidade científica.

As universidades atualmente são responsáveis pelo maior contingente de produção científica mundial; logo, é de se esperar que elas facilitem o diálogo entre comunidade científica e público, levando em consideração vários fatores: seu status de instituição pública e, portanto, a responsabilidade social que esta condição lhe acarreta, que Zémor (1995, apud BRANDÃO, 2006) define em funções como informar, ouvir demandas e assegurar a relação social fazendo do cidadão um ator na sociedade, além de acompanhar as mudanças ocorridas no meio no qual está inserida; a necessidade de se prestar contas com a população que a sustenta por meio dos impostos, viabilizando o fluxo de informações, ajudando a mídia a levar o que é produzido em seus domínios para a população.

Deste modo, a comunidade conhece o que está sendo desenvolvido, compreende como aqueles produtos e descobertas podem ser úteis, e fica ciente do destino que seus impostos têm recebido - podendo, ainda, no futuro, usufruir diretamente dos benefícios gerados por esses avanços. Nesse sentido, Porto (2013, p. 65) afirma que:

O Ciberespaço possibilita transbordamentos e reformatações do espaço de significações, numa produção que acelera os tempos das notícias e pluraliza sua topologia. Com tudo isso abre-se caminho para que o cientista, o pesquisador e o divulgador de ciência possam dinamizar a circulação das informações sobre ciência, em uma escala extremamente potencializada quando comparada com os recursos comunicacionais pré-digitais. 
No entanto, o que se nota é que, embora nunca se tenha investido tanto em ciência a tecnologia, a população tem permanecido cada vez mais alheia à temática, carente de conhecimento técnico-científico.

Tendo em mente, portanto, a função social da mídia, principalmente a jornalística, bem como o dever da universidade de contribuir para o sucesso da empreitada da comunicação pública científica, esta pesquisa se propôs a investigar como (ou se) está sendo feito esse diálogo entre o conteúdo científico produzido nos domínios da Universidade Federal de Uberlândia (UFU) e os dados divulgados pela mídia local, com enfoque na plataforma digital.

\section{Investigação e resultados parciais}

Como fonte da coleta de dados a sucursal do Triângulo Mineiro do portal G1 de notícias foi escolhida, por ser a seção regional de um portal de notícias de expressão nacional, mas com enfoque regional/local. Uberlândia é atualmente a cidade de maior importância do Triângulo Mineiro, e a UFU, com seus campi em algumas cidades da região, se apresenta como o maior pólo de conhecimento local.

Deste modo, infere-se as produções acadêmicas e científicas ocorridas no âmbito universitário seriam de interesse de tal veículo, levando em consideração também o fato de a universidade contar com uma Diretoria de Comunicação Social (DIRCO), cuja função é estabelecer um vínculo entre academia e sociedade, e uma das formas de fazêlo é divulgando, por meio de releases, pesquisas e resultados de estudos feitos na UFU para a mídia local.

A pesquisa foi desenvolvida de forma aplicada, tendo em vista que seu fim se encontra na busca para soluções de problemas concretos (CERVO; BERVIAN, 1976, p.54), que no caso seria a existência e eficiência entre o diálogo com o que é produzido de ciência na universidade e a forma como esses dados chegam a população através dos meios de comunicação.

O trabalho possui viés documental, com pesquisa de campo e qualitativa, pois a investigação foi feita através das notícias e reportagens publicadas no portal G1 do Triângulo Mineiro, o que permite o estudo da realidade presente. O registro desse trabalho inicial dá ao trabalho um caráter descritivo, graças ao registro e análise dos dados coletados. 
O aporte metodológico adotado para analisar o que foi apreendido é o da análise de conteúdo, uma vez que

\begin{abstract}
A análise de conteúdo é sistemática porque se baseia num conjunto de procedimentos que se aplicam da mesma forma a todo o conteúdo analisável. É também confiável - ou objetiva - porque permite que diferentes pessoas, aplicando em separado as mesmas categorias à mesma amostra de mensagens, possam chegar às mesmas conclusões. (LOZANO apud JÚNIOR, 2008, p. 286)
\end{abstract}

Com relação à técnica utilizada, a análise de avaliação foi escolhida, pois ela contempla o posicionamento do locutor - no caso, a mídia digital local representada pelo G1 Triângulo - com relação ao tema em questão e seus objetivos na hora da enunciação. "Parte do princípio de que a linguagem representa e reflete diretamente aquele que o utiliza” (JÚNIOR, 2008, p. 301).

Os dados aqui apresentados foram coletados de novembro de 2013 a 14 de março de 2014. A estratégia utilizada foi valer-se do sistema de buscas do próprio site e buscar pela incidência do nome da universidade entre os arquivos de notícia. Os resultados encontrados foram registrados, e aqueles que possuíam relação com ciência e tecnologia (C\&T) foram separados para posterior análise esmiuçada.

Deste modo, até o mês de março foram encontradas 51 notícias relacionadas à UFU. Desse montante, apenas seis diz respeito específico à com C\&T e/ou pesquisas acadêmicas. Serão analisadas aqui, no entanto, três notícias, uma vez que as outras três, embora estejam relacionadas com a temática da ciência, não possuem o enfoque na pesquisa acadêmica como se intenta analisar no presente trabalho.

As categorias de análise utilizadas são: tamanho (em caracteres), abordagem, linguagem, material gráfico e finalidade.

O primeiro material selecionado foi a notícia "Nova forma de cultivar soja será lançada pela UFU em 2014”, publicada no dia 28 de dezembro de 2013. Sua extensão é de 1211 caracteres com espaço e não há nenhum material gráfico complemento, apenas um vídeo de 2'47” com a versão audiovisual da notícia, veiculada no programa MG Rural.

A abordagem utilizada tem como enfoque o diferencial desse novo tipo de soja e qual será o seu impacto na agricultura. Um professor da UFU é consultado, e uma de suas falas de destaque fala justamente sobre a relevância de se pesquisar novos cultivos e sementes de soja, o que revela uma preocupação em mostrar ao leitor a finalidade daqueles estudos. 
Embora a linguagem seja simples, direta e acessível, sem jargões da agricultura ou da ciência, a abordagem deixa dúvidas com relação ao produto final da pesquisa. A manchete diz respeito a uma nova forma de se cultivar a soja, porém o lead diz respeito ao desenvolvimento de um novo tipo de semente, que recebeu o nome de guará e tem como diferencial de ser tolerante ao mofo branco. Quanto ao procedimento da pesquisa, ele é descrito, ainda que de forma breve e pouco elucidativa.

Com relação à finalidade, pode-se dizer que a notícia teve como objetivo destacar a nova semente da soja e apresentar suas vantagens com relação às sementes existentes na natureza e no mercado. Pode-se atribuir essa escolha ao fato de Uberlândia ser uma cidade importante no ramo do agronegócio, de modo que uma notícia que tem como enfoque novidades para o ramo possui o potencial de chamar atenção de mais leitores.

A segunda notícia, "Professor da UFU ganha prêmio com pesquisa sobre hantavírus”, foi publicada no dia 22 de janeiro de 2014 e possui 3840 caracteres com espaço de extensão.

A matéria possui quatro fotos: a primeira delas traz o professor recebendo o prêmio do Ministério da Saúde, a segunda mostra o mesmo em um laboratório executando testes, a terceira traz a equipe fazendo o trabalho de campo na mata, e a última mostra a equipe de apoio do professor reunida em frente a Zoonoses, vestindo os paramentos de laboratório. Enquanto a primeira imagem ilustra o fato gerador de notícia, a segunda e a última, mostrando os pesquisadores em seu local de trabalho, contribui, de certa forma, para a perpetuação dos estereótipos em torno da figura do cientista do sexo masculino - há o laboratório, as lâminas, o traje especial e o semblante austero, etc. A terceira imagem é a única que pode ser considerada relevante para informar o leitor pois, ao registrar a equipe do professor Jean Ezequiel buscando agentes nas matas, a legenda informa que a hantavirose possui maior incidência no campo, dado que pode ser importante para o leitor.

Já a abordagem utilizada prioriza as motivações da pesquisa e sua relevância para a sociedade de modo geral. É curioso observar que, embora a notícia fale sobre os locais e épocas de maior incidência da doença, não há informação alguma sobre seus efeitos, sintomas e nem o detalhamento sobre sua forma de transmissão. Assim, o leitor leigo pode até se interessar pelo feito do professor, mas não vai conseguir associar aquilo com sua vida e nem ser informado sobre o que provoca a doença, como 
identificá-la ou até preveni-la - e isso se mostra problemático quando o veículo cobre a região que, de acordo com a própria matéria, acumula mais casos da doença no mundo.

Vale destacar também que o processo da pesquisa, seus métodos, etc não são descritos, e os resultados também não são o foco principal.

A linguagem simples, direta e acessível também se observa nessa matéria, cuja finalidade podemos definir como informativa, ainda que de forma superficial. A matéria visa informar o leitor sobre a pesquisa do professor Jean Ezequiel, sua relevância e importância na região, mas não tem enfoque no processo de produção da ciência e nem visa o serviço de abordar de forma prática a hantavirose enquanto doença que pode acometer seu público leitor.

Por fim, a terceira notícia, intitulada "Pesquisa avalia morte de animais em rodovias do Triângulo Mineiro”, foi publicada no dia 18 de fevereiro de 2014 e possui 1384 caracteres de extensão, com espaço. Não há material gráfico, apenas um vídeo para a versão audiovisual da matéria, com 2’14”, veiculada no MGTV.

A abordagem dessa matéria tem como enfoque a pesquisa acadêmica em si, uma vez que descreve os processos realizados pelos biólogos, além daquilo que os dados representam e o que pode ser feito com essas informações. Ainda que esteja em andamento, a notícia traz indicação dos próximos passos da pesquisa. A finalidade, portanto, pode ser entendida como divulgar e, mais importante, explicar uma pesquisa que está sendo realizada no âmbito da universidade, e relatar sua importância para a sociedade. Desta maneira a comunicação pública acontece, pois as pessoas têm acesso, conseguem entender e se enxergar no processo do qual também fazem parte.

Com relação a linguagem, do mesmo modo que nas outras notícias analisadas essa também é escrita de forma objetiva, direta e acessível. No entanto, não faz uso eficaz do hipertexto, que segundo a pesquisa de Porto (2013) sobre a divulgação científica realizada no Brasil através da internet, é uma das principais características dos sites listados como aqueles que possuem maior atualização, memória e interatividade e, também, não sugere a hiperlincagem, característica eminente da forma rizomática de disponibilizar informações na web. 


\section{Considerações finais}

As análises e dados aqui expostos são parte de uma pesquisa que ainda está em andamento, de modo que os resultados não são definitivos, assim como as conclusões dizem respeito àquilo que se sabe até o momento.

Apesar disso, não deixa de ser expressiva a ausência de cobertura sobre C\&T, principalmente com enfoque na pesquisa, no veículo analisado. Do pouco material coletado a respeito do tema nos arquivos do portal, apenas três se relacionam diretamente com a pesquisa e, dentre estes, apenas um pode ser considerado integralmente focado na investigação, com detalhamento no processo de pesquisa, o significado dos resultados e as perspectivas futuras de trabalho.

Infelizmente, observam-se lacunas na abordagem, o que nos afasta da conclusão de que existe, de fato, uma comunicação pública da ciência em sua definição conceitual entre a UFU e a imprensa.

Essa conclusão está em consonância com um cenário que não é apenas brasileiro: em pesquisa a respeito do quadro na Europa e principalmente na Espanha, o comunicólogo Joan Costa (2011) aponta que dois terços dos europeus se consideram mal informados a respeito de ciência e tecnologia, o que representa um entrave direto quando se pensa nos diversos problemas que enfrentamos atualmente que só podem entrar no centro de debate da opinião pública caso haja "sensibilidade política e social" (p. 80) acerca deles, como, por exemplo, o efeito estufa, a clonagem, o uso da energia nuclear, dentre outros.

Como já foi dito, a importância de uma população formada e bem informada a respeito de ciência e tecnologia também se encontra numa esfera mais ampla pois, para o autor: "Unos ciudadanos cientificamente alfabetizados son menos vulnerables a la propaganda, al consumismo, a los discursos dogmáticos, y más críticos y capaces de tomar decisiones fundadas” (COSTA, 2011, p. 81).

Deste modo, nos resta agora a investigação e o entendimento aprofundado de onde está a falha nesse intercâmbio de informações: não há notícias sobre produção de C\&T da UFU por que seus processos e resultados não chegam à mídia ou por que essa imprensa entende que essas notícias não são importantes e/ou interessantes ao seu público e, portanto, não as publicam? E se publicam, por que não aprofundam devidamente na explicação sobre as pesquisas e a sua importância teórica e prática? 
A produção científica realizada no âmbito da universidade deve chegar até a comunidade, não só pelo direito que esta tem de saber os frutos que suas contribuições por meio de impostos têm gerado, mas também pelo seu direito à informação e levando em consideração a função social do trabalho jornalístico, exposta na introdução deste trabalho. É importante ressaltar também que a comunicação pública da ciência promove a inclusão social quando permite que a sociedade esteja em contato com o que é produzido nos centros de conhecimento ao seu redor, e os meios de comunicação são convertidos em veículos que levam a educação e a produção científica para além dos muros da escola.

Com tantas potencialidades em jogo, a investigação faz-se necessária, visando o diagnóstico das problemáticas que aqui se apresentam e a ambição de melhora dos resultados no futuro.

\section{Referências}

BRANDÃO, Elizabeth Pazito. Conceito de comunicação pública. In: DUARTE, Jorge (org.). Comunicação Pública - Estado, mercado, sociedade e interesse público. 2. ed. São Paulo: Atlas S.A., 2009.

dos núcleos Usos e significados do conceito Comunicação Pública. Encontro <http://www.portcom.intercom.org.br/pdfs/38942022201012711408495905478367291786.pdf> . Acesso em: 12 set. 2013.

CERVO, Amado Luiz; BERVIAN, Pedro Alcino. Metodologia Científica. São Paulo: Mc Graw-Hill do Brasil, 1976.

COSTA, Joan. La comunicación Pública de la ciencia. Revista ALAIC, n. 1, 2011.

DUARTE, J. e VERAS, L. (orgs). Glossário de Comunicação Pública. Brasília: Casa das Musas, 2006.

JÚNIOR, Wilson Corrêa da Fonseca. Análise de conteúdo. In: DUARTE, Jorge. BARROS, Antonio (org). Métodos e técnicas de pesquisa em comunicação. 2 ed. 2 reimpr. São Paulo: Atlas, 2008.

KANT, Immanuel. Textos seletos: resposta à pergunta: que é esclarecimento. Petrópolis: Editora Vozes, 2005.

LIPOVETSKY, Gilles. A terceira mulher: Permanência e revolução do feminino. São Paulo: Companhia Das Letras, 2000.

PORTO, Cristiane de Magalhães, Divulgação científica: como as notícias disponíveis na internet contribuem para a formação do jornalista científico e a melhoria da educação no 
país. In: PORTO, Cristiane de Magalhães; BORTOLIERO, Simone (orgs). Jornalismo, ciência e educação : Interfaces. Salvador: UDUFBA, 2013. 